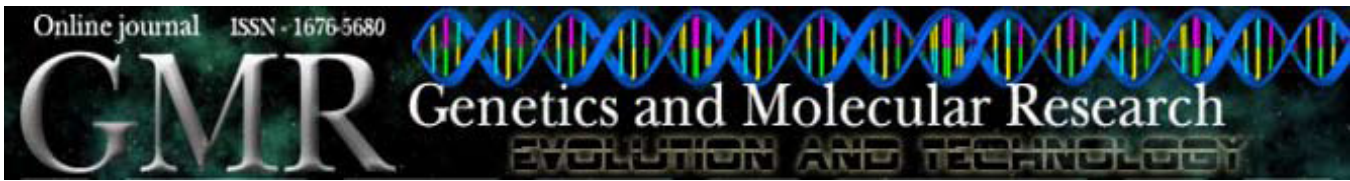

\title{
Association between male infertility and androgen receptor mutations in Brazilian patients
}

\author{
C.O.A. Melo' ${ }^{1}$ A.R. Danin ${ }^{1}$, D.M. Silva ${ }^{1,2}$, J.A. Tacon', \\ K.K.V.O. Moura ${ }^{1}$, E.O.A. Costa ${ }^{1}$ and A.D. da Cruz ${ }^{1,2}$ \\ ${ }^{1}$ Núcleo de Pesquisas Replicon, Departamento de Biologia, \\ Universidade Católica de Goiás, Goiânia, GO, Brasil \\ ${ }^{2}$ LaGene - Laboratório de Citogenética Humana e Genética Molecular, \\ Goiânia, GO, Brasil \\ Corresponding author: D.M. Silva \\ E-mail: danielamelo@ucg.br
}

Genet. Mol. Res. 9 (1): 128-133 (2010)

Received July 23, 2009

Accepted October 27, 2009

Published January 26, 2010

\begin{abstract}
The androgen receptor is encoded by a single-copy gene located in the long arm of the X chromosome (Xq11-12); it consists of eight exons and encodes an intracellular transcription factor that belongs to the steroid/nuclear receptor superfamily. Disturbances in the function of the androgen receptor can lead to several forms of male pseudohermaphroditism, such as androgen insensitivity syndrome, which can lead to infertility. Infertility affects around $20 \%$ of couples, and in half of the cases it is a male problem. Seventy male patients with idiopathic infertility were selected; data were obtained on age, drinking and smoking habits, occupation, and family history. The mean age of the patients was 37 years old (standard deviation = 12.3); $44 \%$ were azoospermic, $33 \%$ were oligozoospermic and $24 \%$ did not have alterations in the spermogram. Our objective was to evaluate a possible association between male infertility and mutations in the androgen receptor gene based on the presence or absence of exons 1 and 4 of this gene. These two exons were tested by PCR, and their products were separated on $1.5 \%$ agarose gels. We found that azoospermic patients had higher mutation rates on exons 1 and 4 of the androgen receptor gene, when compared to other alterations that
\end{abstract}


also lead to infertility, such as oligozoospermia and teratozoospermia. So, we conclude that patients who do not produce sperm have a higher number of mutations in the androgen receptor gene when compared to those who only have impaired sperm production. Based on molecular analysis, we found that there was no correlation between alterations in the spermogram and mutations on exons 1 and 4 of the androgen receptor gene and no association between alterations in the spermogram and alcohol drinking or smoking.

Key words: Male infertility; Androgen receptor; Exon 4; Exon 1; Chromosome X

\section{INTRODUCTION}

The androgen receptor (AR) is encoded by a single-copy gene located in the long arm of the X chromosome (Xq11-12), which consists of eight exons and encodes an intracellular transcription factor that belongs to the steroid/nuclear receptor superfamily (Lubahn et al., 1988). The sequencing of the human AR gene $(A R)$ has allowed researchers to examine the effect of $A R$ mutations on the development of the normal male phenotype, including the development of spermatozoa (Gottlieb et al., 2005).

The AR has four main domains: the amino-terminal activation domain (TAD), comprising exon 1; the DNA binding domain, comprising exons 2 and 3; the hinge domain, and the ligand-binding domain (LBD), comprising exons 4 to 8 (Brinkmann and Trapman, 2000). The receptor is activated when androgen binds to the C-terminal LBD, triggering a cascade of molecular events, including interactions between LBD and TAD, and the recruitment of transcriptional coactivators (Lim et al., 2000).

The development of the male phenotype and the initiation of spermatogenesis, events that lead to the production of male gametes, are dependent on cellular phenomena that respond to androgens. The main androgens in mammals are testosterone and dihydrotestosterone, and the action of both is mediated by the AR (Domenice et al., 2002). Androgen insensitivity syndrome (AIS) is caused by numerous mutations of the $A R$ gene, and it is the major genetic cause of male pseudohermaphroditism. The phenotype may range from partial AIS with ambiguous genitalia to complete AIS with female genitalia (Yong et al., 2003). Recent studies have shown dual post-meiotic roles for the AR during male germ cell differentiation, which consists of terminal differentiation of spermatids and their release from the seminiferous epithelium. Further, progression of spermatids to elongation steps is sensitive to Sertoli cell AR function (Holdcraft and Braun, 2004).

AR has two polymorphic sites in exon 1, characterized by different numbers of CAG and GGC repeats resulting in many extensions of polyglutamine and polyglycine in the amino-terminal domain of the AR protein, which seems to modulate AR function. The number of CAG and GGC repeats can range from 10 to 15 and 4 to 24 , respectively, in normal men. Expansion of the CAG repeat above the normal range has been found to be associated with adult onset of spinal and bulbar muscular atrophy (Ferlin et al., 2004).

Infertility is the inability of a couple to conceive after one year of attempt. This dysfunction can affect around $20 \%$ of couples, and its cause is multifactorial, involving hormonal 
factors, factors related to age, and even psychological causes (Uehara et al., 2001). Idiopathic male infertility, accounting for $40 \%$ of all male infertility cases, is postulated to have a genetic basis (Gottlieb et al., 2005). Stress, genetic mutations and chromosome abnormalities can cause disturbances in chemical events that occur during spermatogenesis (Sailer et al., 1995; Lopes et al., 1998).

Infertile men have several nuclear alterations, including an abnormal structure of chromatin, chromosomes with microdeletions and DNA breaks (Fuentes-Mascorro, 2000).

This study evaluated Brazilian patients to determine the association between male infertility and the $A R$ gene, based on the presence or the absence of exons 1 and 4 of this gene. The present study is only an initial research into the causes of idiopathic male infertility.

\section{PATIENTS AND METHODS}

Seventy male patients with idiopathic infertility were evaluated. All these patients lived in Goiânia, GO, Brazil, and the clinical data were obtained at the first medical visit to the Serviço de Reprodução Assistida of Hospital das Clínicas de Goiânia, in the year of 2006. Such clinical data included age, drinking and smoking habits, occupation, and family history. As a control group, we selected 25 healthy men, with at least, one biological child.

\section{Molecular analysis}

The $A R$ gene is located in the $\mathrm{Xq} 11-12$ region. DNA samples obtained from peripheral blood lymphocytes and semen were submitted to polymerase chain reaction (PCR) amplification, employing primers targeting exons 1 and 4 of the $A R$ gene. The sense primer of exon 1 was synthesized as follows: 5' CGG GTT CTC CAG CTT GAT GCG 3'. The antisense primer was 5' GCT CCC ACT TCC TCC AAG GAC AAT TAC 3'. The sense primer of exon 4 was 5' ACA CTA CAC CTG GCT CAA TGG 3' and the antisense was 5' CGG AAG CTG AAG AAA CTT GG 3'. The final PCR included a 10X buffer, $50 \mathrm{mM} \mathrm{MgCl}_{2}, 500 \mathrm{U}$ Taq DNA polymerase, $10 \mu \mathrm{M}$ oligonucleotides, specific for exons 1 and 4 of the $A R$ gene, $25 \mathrm{mM}$ of each dNTP and Milli-Q $\mathrm{H}_{2} \mathrm{O}$ to obtain a final volume of $25 \mu \mathrm{L}$. PCR was performed in a GeneAmp PCR system 9700 thermocycler (Perkin-Elmer, USA) under the following conditions: initial denaturing step at $95^{\circ} \mathrm{C}$ for $3 \mathrm{~min}$, followed by 35 cycles of denaturation, annealing and extension $\left(95^{\circ}\right.$ for 1 min, $56^{\circ}$ for $1 \mathrm{~min}$ and $72^{\circ}$ for $1 \mathrm{~min}$, respectively). A final extension at $72^{\circ} \mathrm{C}$ for $5 \mathrm{~min}$ was also performed. For analysis of the products obtained by PCR, the material amplified was submitted to electrophoresis on $1.5 \%$ agarose gels and stained with $5 \mu \mathrm{g} / \mathrm{mL}$ ethidium bromide. A visual record of the gels was made with a videodocumentation system (Image Master VDS ${ }^{\circledR}$ - Amersham Pharmacia Biotech, USA).

\section{Statistical analysis}

We examined if age was significantly different for the azoospermic and oligozoospermic patients. To test this hypothesis, the Student $t$-test was used to determine a possible association between the presence or absence of exons 1 and 4 and infertility status and also to determine the relation between the number of patients that showed alterations on the spermogram and the frequency of alcohol drinkers and smokers. 


\section{RESULTS}

The mean age of the patients was 37 years ( $\mathrm{SD}=12.3$ years) and the mean age of the control group was 40 years ( $\mathrm{SD}=10.5$ years). All healthy men showed both exons 1 and 4 .

We found more azoospermic patients (43.63\%) related to other alterations on the spermogram, as shown in Table 1. This study also showed that azoospermic patients reported drinking and smoking habits, as shown in Table 2. As shown in Table 3, the number of mutations in azoospermic patients was higher $(66.6 \%$ on exon 1 and $56.25 \%$ on exon 4$)$ than in oligozoospermic patients ( $11.1 \%$ on exon 1 and $18.75 \%$ on exon 4$)$.

Table 1. Spermogram results and the number of patients with sperm alterations.

\begin{tabular}{lcc}
\hline Diagnosis at spermogram & Number of patients & Percent \\
\hline Azoospermia & 24 & $43.63 \%$ \\
Oligospermia & 18 & $32.72 \%$ \\
Others $^{1}$ & 13 & $23.63 \%$ \\
Total & 55 & $100 \%$ \\
\hline
\end{tabular}

${ }^{1}$ Term corresponding to the combination of oligospermia/teratospermia and oligospermia/asthenospermia.

Table 2. Number of patients who showed alterations in spermogram and the frequency of drinkers and smokers.

\begin{tabular}{lcccr}
\hline Diagnosis at spermogram & Number of drinkers & Percent & Number of smokers & Percent \\
\hline Azoospermia & 8 & $50 \%$ & 1 & $25 \%$ \\
Oligospermia & 6 & $37.5 \%$ & 1 & $50 \%$ \\
Others $^{1}$ & 2 & $12.5 \%$ & 4 & $25 \%$ \\
Total & 16 & $100 \%$ & $100 \%$ \\
\hline
\end{tabular}

${ }^{1}$ Term corresponding to the combination of oligospermia/teratospermia and oligospermia/asthenospermia.

Table 3. Number of patients who showed alterations in spermogram and mutations on exons 1 and 4 of the $A R$ gene.

\begin{tabular}{lcccc}
\hline Diagnosis at spermogram & $\begin{array}{c}\text { Number of patients with } \\
\text { mutation on exon 1 }\end{array}$ & Percent & $\begin{array}{c}\text { Number of patients with } \\
\text { mutation on exon } 4\end{array}$ \\
\hline Azoospermia & 6 & $66.6 \%$ & 9 & $56.25 \%$ \\
Oligospermia & 1 & $11.1 \%$ & 3 & $18.75 \%$ \\
Others & 2 & $22.2 \%$ & 4 & $25 \%$ \\
Total & 9 & $100 \%$ & 16 & $100 \%$ \\
\hline
\end{tabular}

${ }^{1}$ Term corresponding to the combination of oligospermia/teratospermia and oligospermia/asthenospermia.

In this study, we found that azoospermic patients clearly had higher mutation rates on exons 1 and 4 of the $A R$ gene, when compared to other alterations that also lead to infertility, such as oligozoospermia and teratozoospermia. We can conclude that patients who do not produce sperm have a higher number of mutations in the $A R$ gene when compared to those who only have an impaired sperm production, as in oligozoospermic and teratozoospermic patients. There was no difference in age between the azoospermic and oligospermic patients $(\mathrm{P}=0.007)$.

\section{DISCUSSION}

Although we found in the present study that azoospermic patients have much higher mutation rates on exons 1 and 4 of the $A R$ gene, compared to other changes that also lead to infertility, 
such as oligozoospermia and teratozoospermia, statistical analysis showed that there was no correlation between the diagnosis of spermogram and mutations on exons $1(\mathrm{P}=0.26)$ and $4(\mathrm{P}=0.39)$ of the $A R$ gene. Such findings could be explained by the small sample size of the group analyzed.

We also did not find any correlation between the diagnosis from the spermogram and alcohol drinkers and smokers $(\mathrm{P}=0.30$ and $\mathrm{P}=0.24$, respectively), although it has been reported that cigarette smoking affects sperm DNA integrity (Kunzle et al., 2003). Eskenazi et al. (2003) performed a study to evaluate the relationship between seminal volume and drinking and smoking habits, and they concluded that the sperm quality is decreased in men who have these habits during their life.

Cigarette smoke has mutagenic properties, having been associated with an overall reduction in semen quality, and specifically a reduction in sperm count and motility and an increase in number of abnormal cells. However, we could not find a statistically significant difference between spermogram results and lifestyle (alcohol and smoking), probably due to the small sample size or to the amount of cigarettes or alcohol used by our patients, since we did not quantify such variables in our protocols.

Some studies (Yong et al., 2003; Ferlin et al., 2004; Holdcraft and Braun, 2004) have examined the possible link between the length of the CAG repeat that codes for the polyglutamine tract on exon 1 of AR and male infertility. Those studies found that the length of the polyglutamine repeat is inversely proportional to the degree of normal functionality of AR. This observation has led to the hypothesis that longer polyglutamine tracts may possibly be considered a risk factor for male infertility. Other studies did not find this association. Studies on Asian and European populations have suggested that different environmental influences may be the cause of these very different findings (Gottlieb et al., 2005).

Yong et al. (2003) reported that most mutations described in the carboxy-terminal domain of AR, which includes exons 4 to 8, can lead to a defect in androgen binding and the loss of receptor function. Genetic examinations of male infertility revealed many loci in the carboxy-terminal domain of AR that are associated with male infertility. On the other hand, not all mutations in the carboxy-terminal domain that cause reduction in sensitivity to androgens result in infertility, which could be the case in our study.

Reported here are preliminary findings in men who presented idiopathic infertility. Therefore, definitive data on the role of AR mutations in male infertility are not yet available, and additional studies in well-defined populations of infertile men of different ethnic origins should be performed. In our case, more extensive investigations, with other exons could be necessary to confirm the initial findings, since mutations in the $A R$ gene are not yet investigated in the Brazilian population, which shows admixture, making it difficult to divide into ethnic groups.

\section{REFERENCES}

Brinkmann AO and Trapman J (2000). Genetic analysis of androgen receptors in development and disease. $A d v$. Pharmacol. 47: 317-341.

Domenice S, Costa EMF, Corrêa RV and Mendonça BB (2002). Molecular aspects of sexual determination and differentiation. [Aspectos moleculares da determinação e diferenciação sexual]. Arq. Bras. Endocrinol. Metab. 46: 433-443.

Eskenazi B, Wyrobek AJ, Sloter E, Kidd SA, et al. (2003). The association of age and semen quality in healthy men. Hum. Reprod. 18: 447-454.

Ferlin A, Bartoloni L, Rizzo G, Roverato A, et al. (2004). Androgen receptor gene CAG and GGC repeat lengths in idiopathic male infertility. Mol. Hum. Reprod. 10: 417-421.

Fuentes-Mascorro G, Serrano H and Rosado A (2000). Sperm chromatin. Arch. Androl. 45: 215-225.

Genetics and Molecular Research 9 (1): 128-133 (2010)

CFUNPEC-RP www.funpecrp.com.br 
Gottlieb B, Lombroso R, Beitel LK and Trifiro MA (2005). Molecular pathology of the androgen receptor in male (in)fertility. Reprod. Biomed. (Online) 10: 42-48.

Holdcraft RW and Braun RE (2004). Androgen receptor function is required in Sertoli cells for the terminal differentiation of haploid spermatids. Development 131: 459-467.

Kunzle R, Mueller MD, Hanggi W, Birkhauser MH, et al. (2003). Semen quality of male smokers and nonsmokers in infertile couples. Fertil. Steril. 79: 287-291.

Lim J, Ghadessy FJ, Abdullah AA, Pinsky L, et al. (2000). Human androgen receptor mutation disrupts ternary interactions between ligand, receptor domains, and the coactivator TIF2 (transcription intermediary factor 2). Mol. Endocrinol. 14: 1187-1197.

Lopes S, Jurisicova A, Sun JG and Casper RF (1998). Reactive oxygen species: potential cause for DNA fragmentation in human spermatozoa. Hum. Reprod. 13: 896-900.

Lubahn DB, Joseph DR, Sullivan PM, Willard HF, et al. (1988). Cloning of human androgen receptor complementary DNA and localization to the X chromosome. Science 240: 327-330.

Sailer BL, Jost LK and Evenson DP (1995). Mammalian sperm DNA susceptibility to in situ denaturation associated with the presence of DNA strand breaks as measured by the terminal deoxynucleotidyl transferase assay. J. Androl. 16: 80-87.

Uehara S, Hashiyada M, Sato K, Sato Y, et al. (2001). Preferential X-chromosome inactivation in women with idiopathic recurrent pregnancy loss. Fertil. Steril. 76: 908-914.

Yong EL, Loy CJ and Sim KS (2003). Androgen receptor gene and male infertility. Hum. Reprod. Update 9: 1-7. 